\title{
Development and Experimental Test Validation with a New High Efficiency LED Driver
}

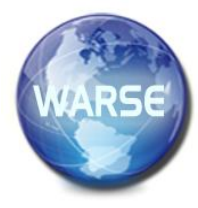

\begin{abstract}
This paper presents a novel high efficiency LED driver. The developed version of the LED driver is based on an active AC-DC converter with a flyback topology. A feature of the proposed circuit is the use of a current / voltage stabilizer on the primary side based on microcontroller FL7733A and a passive stabilizer on the secondary side. The methodology for calculating the rms current values is presented. An experimental sample of the LED driver was designed and assembled according to the proposed scheme. Functional tests have been carried out, which show a qualitative advantage in contrast to the standard circuit of the LED driver. Temperature tests were carried out, it can be seen from them that the driver elements do not experience excessive temperature loads and operate in normal temperature limits.
\end{abstract}

Key words: LED, Driver, Flyback, Converter, Stabilizer

\section{INTRODUCTION}

Due to the specifics of the operation of the LEDs, a voltage or current stabilizer is required to limit the voltage of the LEDs to safe values, in addition, the stabilizer must provide current ripples within the acceptable values of no more than $5 \%$ in the general case. The use of linear regulators as current stabilizers for LEDs is possible, but not acceptable in many cases from the point of view of efficiency. Losses on the linear regulator can negate the use of expensive, yet, but economical LED lighting. Moreover, the gain from the use of LED lighting is precisely in saving on energy costs. Due to the large power losses on the linear stabilizer, it is necessary to take measures to remove heat from the linear element, which can lead to a rise in price, despite the apparent cheapness of the solution. The cheapest option for heat dissipation - using a radiator - affects the increase in size [13].

The most effective solution for protecting and stabilizing the current, and therefore stabilizing the luminous flux of the lighting device, is the use of pulse converters. The wellknown topologies of converters used in LED lighting can be either without galvanic isolation, or with galvanic isolation, see Figure 1.

According to safety requirements, LED lamps must be galvanically isolated to minimize leakage currents and equalizing currents that are hazardous to human health and life. Electronic sources produced for industrial and office use

are designed exclusively on the basis of topologies with galvanic isolation, and the most common schemes are a flyback converter (Figure 1., d) and a resonant LLC converter (Figure 1., e) [6-12]. The advantage of the flyback converter is the simplicity of the circuit. However, lower efficiency, due to which its use is justified with LEDs with power up to $100-150 \mathrm{~W}$, when resonant LLCs are used at powers above 150 watts.
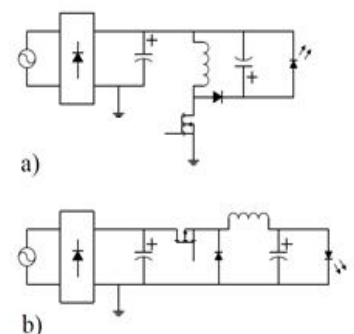

b)

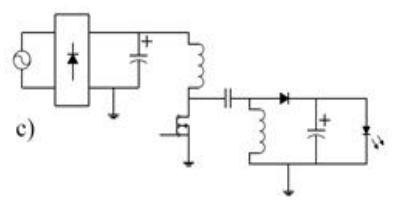

Figure 1: Transformer circuit topologies are presented: without galvanic isolation: a) lowering-raising (buck-boost), b) lowering (buck), c) SEP1C. With galvanic isolation: d) flyback, e) LLC resonant converter

\section{SCHEMATIC SOLUTION}

An innovative LED driver circuit was designed (Figure 2). This scheme uses an innovative simplified control scheme. This circuit involves the use of primary current control and a passive linear regulator.

Figure 2. shows the developed 60W power supply for LED lighting. The LED driver was designed for industrial and office use, for a variable network with a rated voltage of 140$275 \mathrm{~V}$, and the ability to work up to $300 \mathrm{~V}$. The universal and most demanded driver model with a power of $60 \mathrm{~W}$ and an output voltage of $60 \mathrm{~V}$ was selected as far as possible. The most common driver models are presented near 24 to $100 \mathrm{~W}$ and output voltages from 12 to $170 \mathrm{~V}$. 


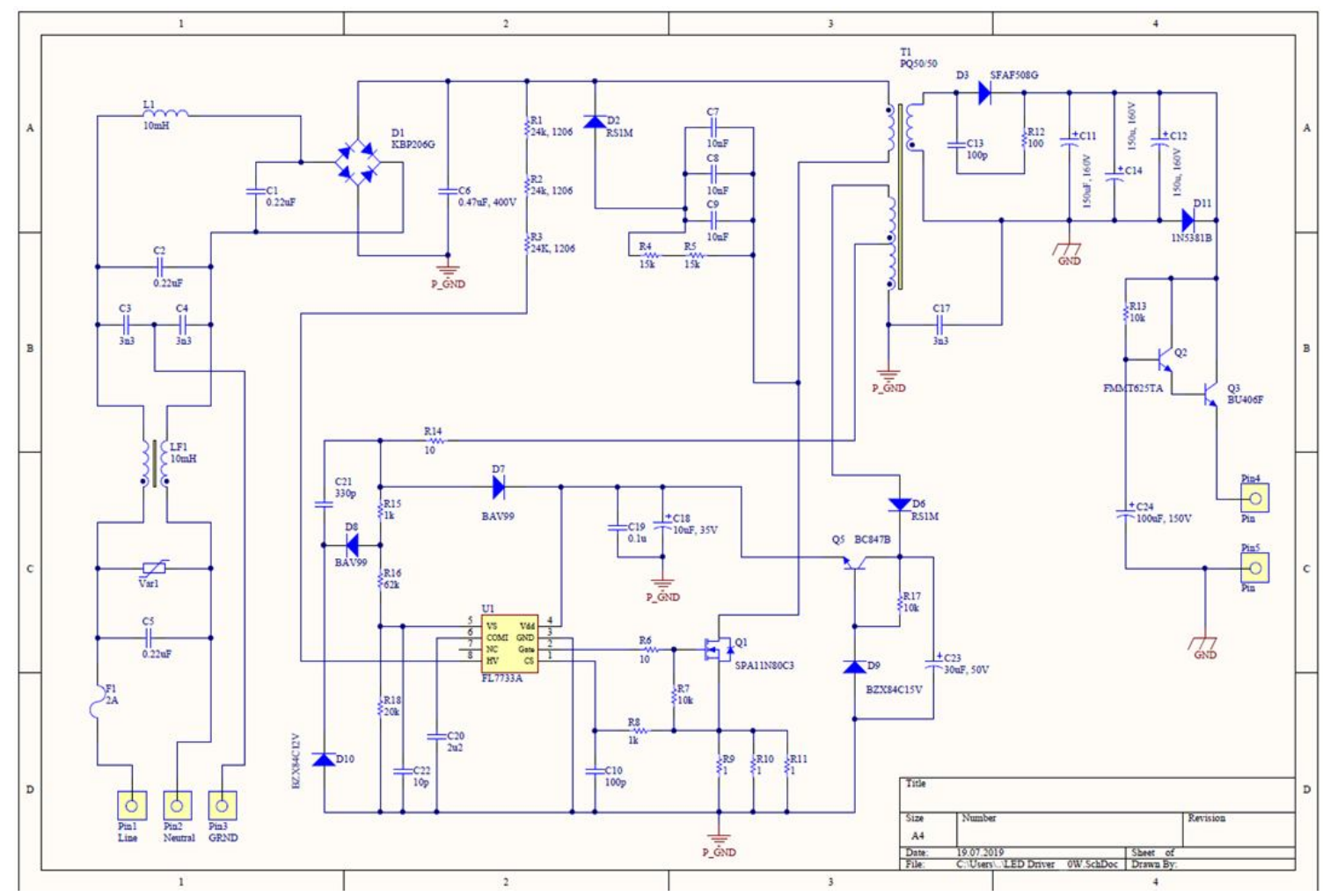

Figure 2: LED driver circuit

Therefore, it seems correct to develop a power source for average power and output voltage, so that in the future, if necessary, you can make changes to the developed source to expand the line. In Fig. 2. the driver consists of the main building blocks: fuse F1, protection against high-voltage surge surges (lightning protection) Var1, input filter for suppressing high-frequency interference, diode rectifier D1, control circuit, regulator of voltage / current of LEDs, output filter - These are the main components of a modern stabilizer. High-quality current / voltage stabilizers that meet the requirements for electromagnetic compatibility, safety, reliability of the LED lamp, high efficiency, contain all of these structural blocks.

The fuse $\mathrm{Fl}$ is required for installation and is designed to prevent fire in the event of a source failure, is selected with a permissible operating current above the current consumption of the driver and taking into account inrush currents.

Varistor Var 1 protects the LED driver from impulse noise on the input to meet the immunity requirements of the electronic device for interference on networks. If the maximum input AC voltage is $300 \mathrm{~V}$, then the value of the varistor voltage should be in the range $450-750 \mathrm{~V}$. At the same time, in order to meet the requirements of immunity to interference over networks, the fuse and varistor are selected so that the fuse does not blow out at a short-time high-voltage pulse voltage in the network when the varistor comes into operation, absorbing pulse energy.

Input components: capacitance C5 (class X2), inductance LF1, capacitance $\mathrm{C} 1$ (class X2), capacitance C2 (class $\mathrm{Y} 1$ ), capacitance C3 (class Y1), capacitance C4 (class Y1) form an electromagnetic interference input filter. The input filter is designed to suppress electromagnetic interference generated by the LED source and is very effective in combating conducted (by wire) interference and radiated interference.

The LED stabilizer consists of a primary MOSFET key Q1, a transformer T1, a rectifier diode D3 on the secondary side and a controller chip FL7733A. The stabilizer is designed on the basis of a flyback converter with galvanic isolation. The stabilizer controller FL7733A provides flyback operation in the regime of discontinuous currents, while using a signal from the auxiliary power winding to stabilize the output voltage. This reduces the number of components needed to organize feedback.

The power semiconductor components of the transistor Q1 and the rectifier diode D3 of the stabilizer, are selected on the basis that the mode of operation does not go beyond their safe area specified in the specifications for the components. In addition, power semiconductors are selected for reasons of price and optimization of power losses. As a rule, semiconductor components selected for reasons of loss optimization under the existing operating conditions in the product have a sufficient area of safe operation, that is, the values of their permissible currents and voltages are sufficiently higher than the required minimum. The power losses in the power semiconductors of the pulse converter are the sum of the conductive losses (ohmic losses in field effect transistors or at a direct transition in diodes) and dynamic losses, that is, switching losses. As a rule, minimal losses are achieved when a semiconductor is selected for which the conductive and dynamic losses are equal (balanced).

\section{STABILIZER ANALYSIS}

As can be seen in the diagram on the primary side, the FL7733A chip was used to stabilize the current. A passive linear stabilizer on the secondary side before output. Consider the operation of the converter in more detail [13-17]. The diagram in Figure 3. clearly shows the time steps of the converter. In step 1: during (Ton) turning on the MOSFET of transistor Q1, the input voltage $\mathrm{Vdl}$ (at the input capacitor $\mathrm{Cdl}$ ) is applied to the primary side of transformer T1. The current Ids of the transistor Q1 increases linearly with time: 


$$
I_{d s}(t)=\frac{V_{d l}}{L 1} \cdot t
$$

to maximum $\mathrm{I}_{\mathrm{pk}}$ value:

$$
I_{p k}=\frac{V_{d l}}{L 1} \cdot T_{o n}
$$

where $\mathrm{L} 1$ is the inductance of the bias of the primary side of the transformer. During this time, energy from the network accumulates in the transformer T1. Let Po be the output power of the converter, then the average input current of the converter for the switching period Iin $=\mathrm{Po} / \mathrm{Vdl}$. It is not difficult to calculate from the charge balance that the average input current and peak current are related by the relation: Ton*Ipk/2=Tsw*Iin, where Tsw is the switching period of the main key Q1. It is not difficult to find from (2) the dependence determining the necessary time for the main key to be turned on from the load and circuit parameters:

$$
T_{o n}=\frac{\sqrt{2 P_{0} \cdot L 1 \cdot T_{s w}}}{V_{d l}}
$$

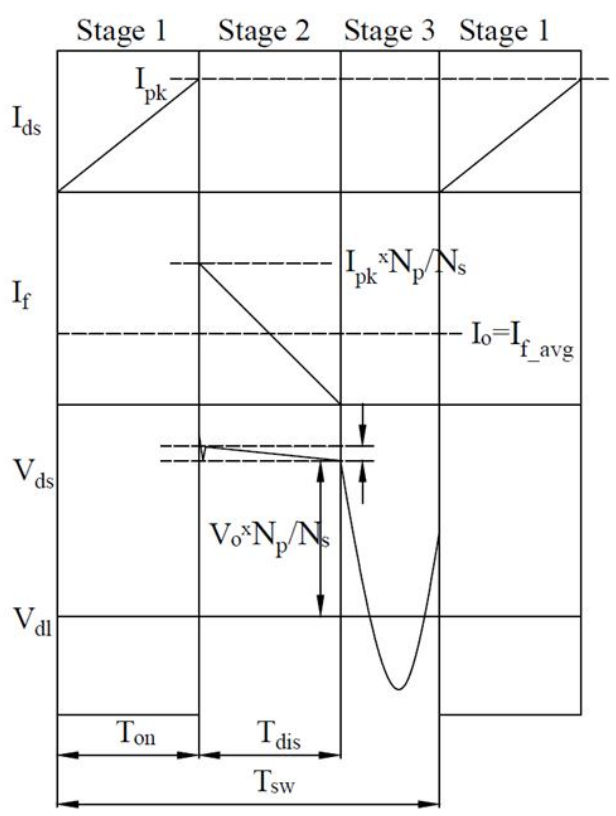

Figure 3: Transmitter phase diagram (Flyback)

In step 2: during the time Tdis, the transistor Q1 is turned off, the energy stored in the transformer T1 is released through the diode Df on the secondary side T1, charging the output capacitor Co. While the diode Df conducts, the sum of the output voltage Vo and the forward voltage $\mathrm{Vf}$ at the diode are applied to the secondary side of the transformer. The secondary current If decreases linearly with time from the maximum value Ipk $* \mathrm{~Np} / \mathrm{Ns}$ to zero at the end of the stage:

$$
I_{f}(t)=I_{p k} \frac{N_{p}}{N_{s}}-\frac{V_{0}}{L 2} \cdot t
$$

where $\mathrm{N}_{p}$ and $\mathrm{N}_{\mathrm{s}}$ respectively the number of windings on the primary and secondary sides, a L2:

$$
L 2=\left(\frac{N_{s}}{N_{p}}\right)^{2} \cdot L 1
$$

- bias inductance of the secondary side. From (4) it is not difficult to find that the discharge time is determined by the formula:

$$
T_{d i s}=\frac{N_{s}}{N_{p}} \cdot \frac{\sqrt{2 P_{0} \cdot L 1 \cdot T_{s w}}}{V_{0}}
$$

In this case, the condition of discontinuous currents should be satisfied when the discharge time is less than the time of the closed state of the Q1 switch: Tdis < Toff = Tsw - Top, or in another way: Ton + Tdis < Tsw.

At stage 3: when the secondary winding current If reaches zero, as a result of the locking process of the diode Df, the reverse voltage of the diode increases, the voltage on the secondary side of the transformer $\mathrm{T} 1$ and the voltage $\mathrm{Va}$ on the auxiliary winding decrease. The voltages on the transformer windings begin to oscillate due to the resonance between the magnetization inductance of the transformer T1 and the effective output capacitance of the transistor Q1.

To select the optimal components of the circuit, it is useful to find the current values of the currents on the primary and secondary side. The current values of the currents will be calculated by the well-known formula:

$$
I_{r m s}=\sqrt{\frac{1}{T_{s w}} \cdot \int_{0}^{T_{s w}} I(t)^{2} d t}
$$

After simple calculations, we obtain for the effective value of the primary side:

$$
I_{r m s 1}=\sqrt{\frac{1}{T_{s w}} \cdot \int_{0}^{T_{o n}}\left(\frac{I_{p k}}{T_{o n}} \cdot t\right)^{2} d t}=I_{p k} \sqrt{\frac{T_{o n}}{3 \cdot T_{s w}}}=I_{i n} \sqrt{\frac{4 \cdot T_{s w}}{3 \cdot T_{o n}}}
$$

For the effective value of the secondary side:

$$
\begin{aligned}
& I_{r m s 2}=\sqrt{\frac{1}{T_{s w}} \cdot \int_{0}^{T_{d i s}}\left(\frac{N_{p}}{N_{s}} \cdot \frac{I_{p k}}{T_{d i s}} \cdot t\right)^{2} d t}=\frac{N_{p}}{N_{s}} \cdot I_{p k} \sqrt{\frac{T_{d i s}}{3 \cdot T_{s w}}}= \\
& =\sqrt{\frac{N_{p} \cdot V_{d l}}{N_{s} \cdot V_{0}}} \cdot I_{i n} \sqrt{\frac{4 \cdot T_{s w}}{3 \cdot T_{o n}}}
\end{aligned}
$$

Knowing the current values of the currents in the circuit circuits, it is possible to calculate the loss of conductivity (ohmic losses, and losses at the direct transition in diodes) of electronic elements - magnetic (coil) components and semiconductors. To get an idea of the total losses of electronic elements (components) of the circuit, you need to calculate their dynamic losses, that is, losses on switching or magnetization reversal in the case of magnetic components. Choosing the best electronic component will come down to choosing a component with minimal total power loss [18-25]. 


\section{EXPERIMENTAL SAMPLE}

The FL7733A is an Active Power Factor Correction (PFC) controller used in a single-stage feedback topology or low gain topology (Figure 4) [23].

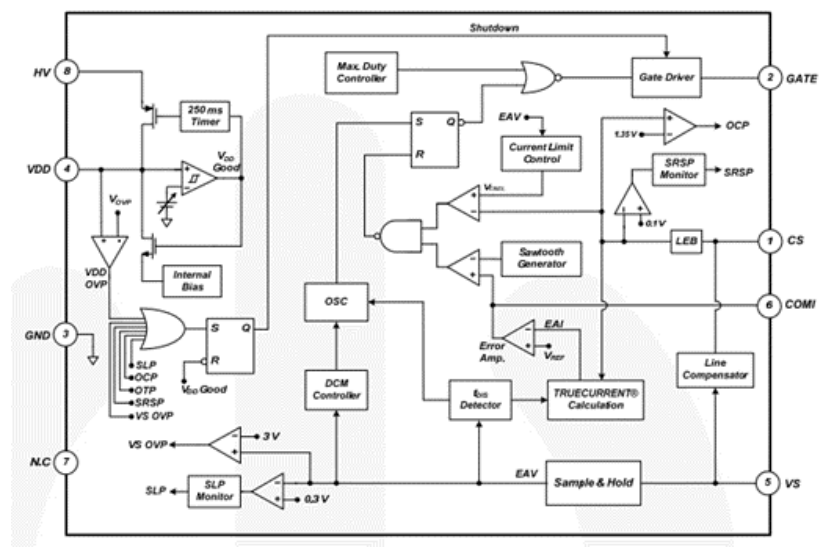

Figure 4: Block diagram FL7733A

Primary side control and single-stage topology reduce external components such as input capacitors and feedback circuits, minimizing cost. To improve power factor and total harmonic distortion (THD), continuous time control is used with an internal error amplifier and low bandwidth compensator. Precise constant control regulates the exact output current, regardless of the input voltage and output voltage. The operating frequency is proportionally varied by the output voltage to ensure intermittent current (DCM) operation, which ensures high efficiency and simple construction. FL7733A provides protection against the maximum voltage of LEDs with open circuit, short circuit current of LEDs and overheating. Figure 5 shows a typical FL7733A wiring diagram. The fundamental difference in the implementation proposed by us and the standard schemes is the use of a passive stabilizer on the secondary side and some schematic changes on the primary side. The improvements we have made are reflected in the comparison of the two schemes during functional tests. According to the LED driver diagram, templates were designed for the upper and lower sides of the PCB Figure 6 (a). The laboratory sample of the LED power supply (driver) was assembled and debugged, Figure 6 (b).

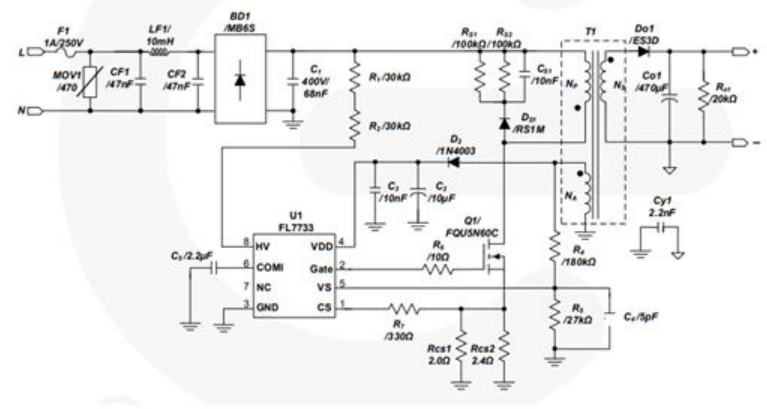

Figure 5: Typical circuit using FL7733A
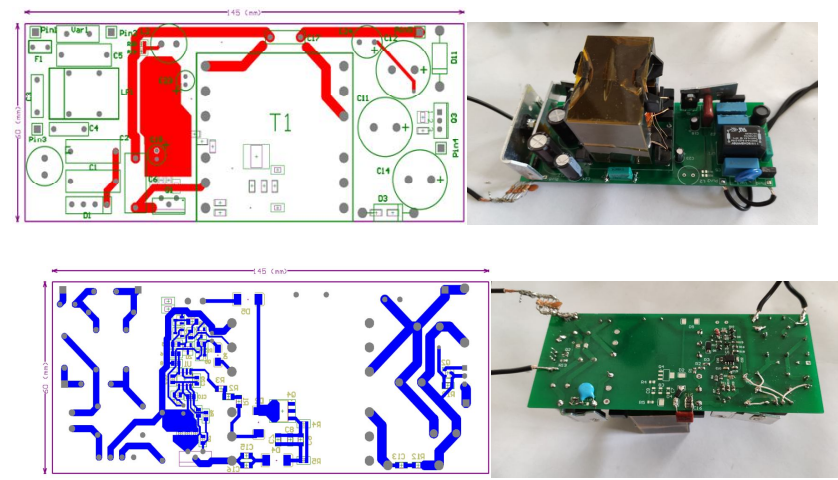

a)

b)

Figure 6: Top and bottom plans of the LED driver circuit board and a laboratory sample of the LED driver top and bottom view

\section{EXPERIMENTS}

Functional tests of an experimental laboratory sample of an innovative $60 \mathrm{~W}$ LED driver were carried out. The experiment was performed at various input voltages, in particular $160 \mathrm{~V}$ and $220 \mathrm{~V}$.

As can be seen from the graphs (Figure 7) in both cases, at 160 and $220 \mathrm{~V}$, the picture is identical at the outputs. By the time the cycle starts, the transformer core is completely demagnetized, and there is no current in it. At the moment when a control signal is supplied from the PWM controller, the power switch Q1 opens and the current in the transformer begins to increase. A current surge occurs associated with the charge of the stray capacitance of the transformer. The output diode is also completely closed by this time. Next, the power transistor turns off, the current in it drops sharply from Ipk to zero, and the voltage begins to increase rapidly and reaches VMAX. By the next moment, the current in the secondary winding of the transformer completely stopped, and the output diode closed. Therefore, the transformer is "suspended in the air", and relatively low-frequency oscillations occur on its primary winding caused by the oscillating circuit from the magnetization inductance of the transformer and some equivalent capacitance formed by the inter-turn / inter-winding capacity and the output capacity of the power switch. Then the power key opens and the process repeats. 


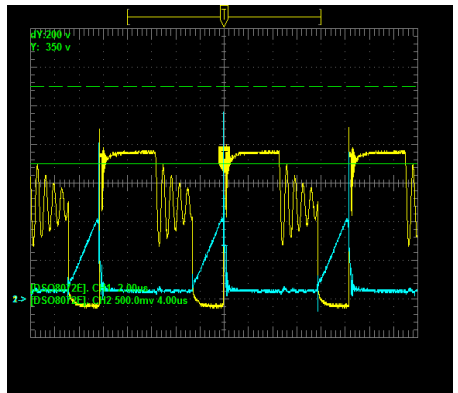

(a) Key voltage and current on the primary side at Vin $=160 \mathrm{~V}$.

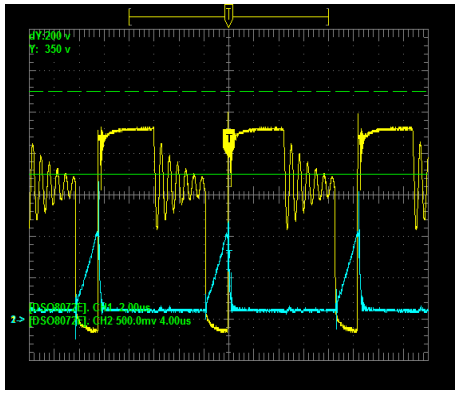

(a) Key voltage and current on the primary side at Vin $=220 \mathrm{~V}$.

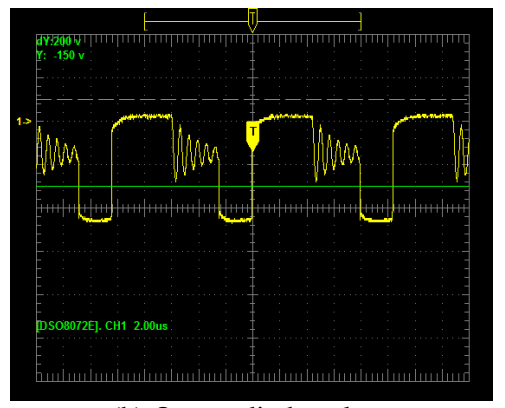

(b) Output diode voltage on the secondary side at Vin $=160 \mathrm{~V}$.

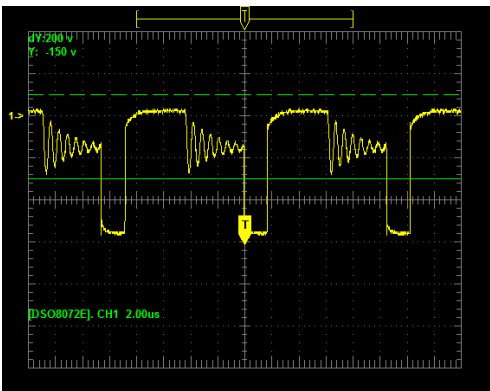

(b) Output diode voltage on the secondary side at Vin $=220 \mathrm{~V}$.

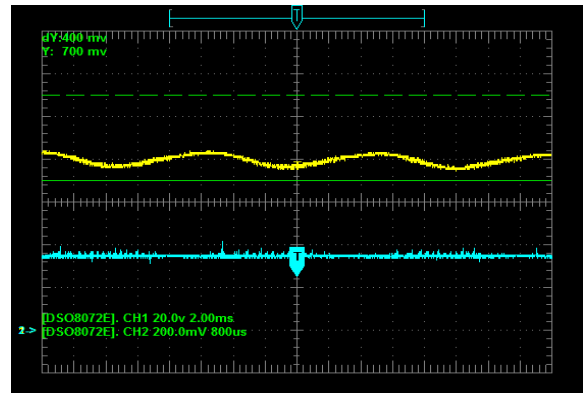

(c) Output voltage and current at Vin $=160 \mathrm{~V}$.

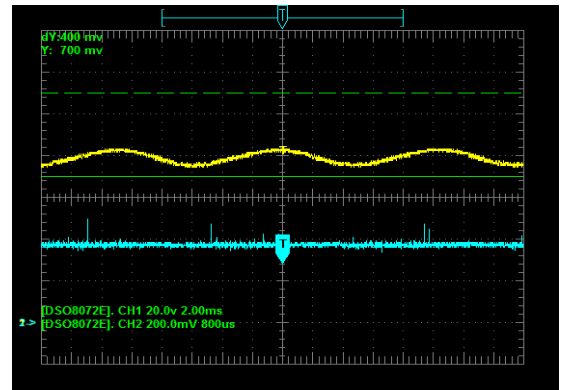

(c) Output voltage and current at Vin $=220 \mathrm{~V}$.

Figure 7: Voltage and current graphs of the LED driver

On the graphs (Figure 7), all the described stages of the driver's operation occur in normal mode, the maximum voltage that occurs when the current is turned off by the key Q1 lies within the limits allowed by the circuit components, i.e. does not exceed the permissible limit voltage on the key and diodes. In the case of an input voltage of $160 \mathrm{~V}$, the maximum VMAX voltage reached $400 \mathrm{~V}$, and at $220 \mathrm{~V}$ it reached $600 \mathrm{~V}$. The components that are used in the circuit can operate at a voltage of $800 \mathrm{~V}$, which allows you to not be afraid of failure when the input voltage drops. On the secondary side, similarly, the voltage drops lie within the permissible norm of the output diode. It is important to note that the output current measured at various voltages is perfectly even (Figure 7). This is achieved through the use of a passive stabilizer at the output of the circuit. Compared with the tests of the standard circuit for the FL7733A microcircuit (Figure 8), our circuit compares favorably with direct current at the output, when, as in the standard circuit, there are fluctuations in the current of small amplitude with the frequency of the input voltage, which negatively affects the flicker of the supplied diodes.
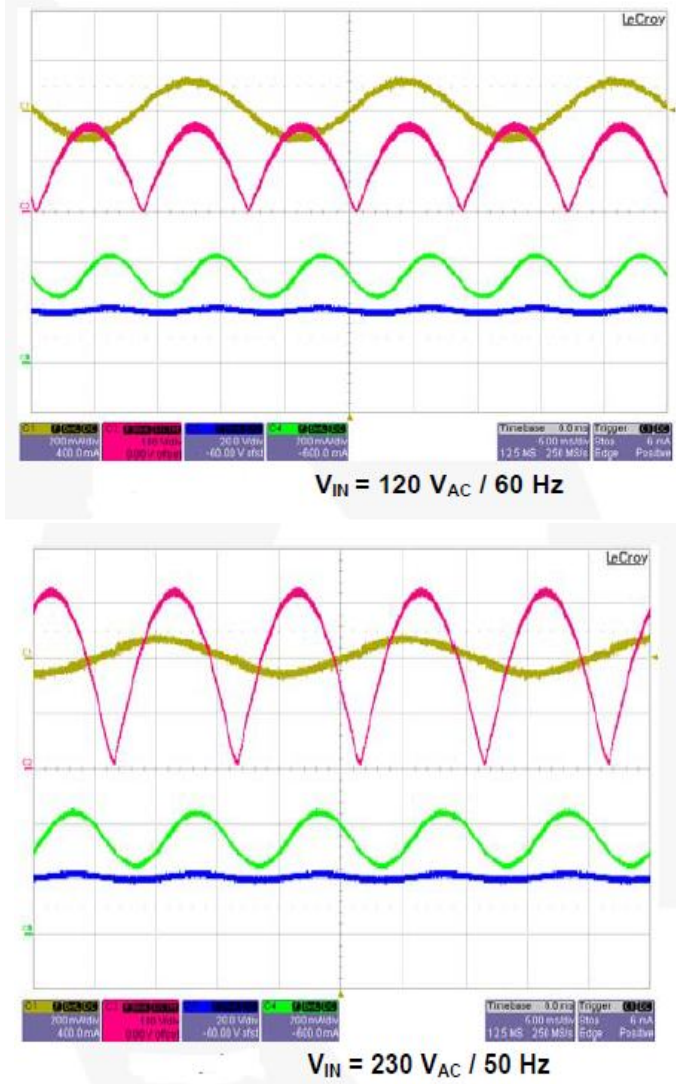

Figure 8: Input and output voltage and current in a standard circuit with FL7733A 


\section{THERMAL TESTS}

Thermal tests were performed for an experimental laboratory sample of an innovative LED driver.

During testing, the innovative driver was connected to an external network and at the output to the diodes so that the power consumed by the LEDs did not exceed 60 watts. Figure 9 show maps of temperature conditions from above and below. The measurement was made on a special thermal imager after 1 hour of driver operation, which is enough to stabilize the temperature in the system. Typically, the temperature of the circuit is stabilized within $30-40$ minutes.

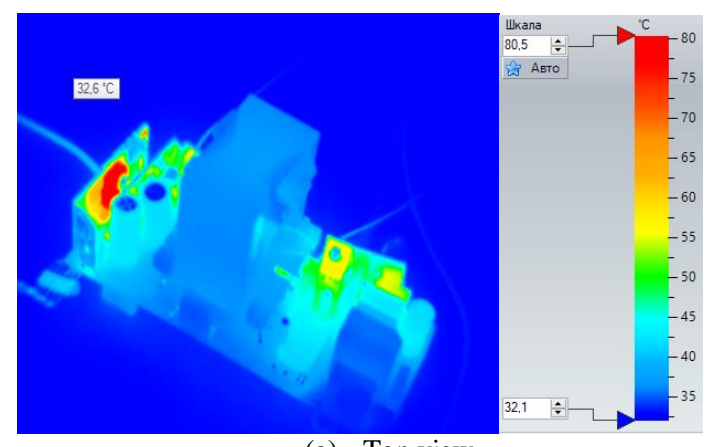

(a) Top view

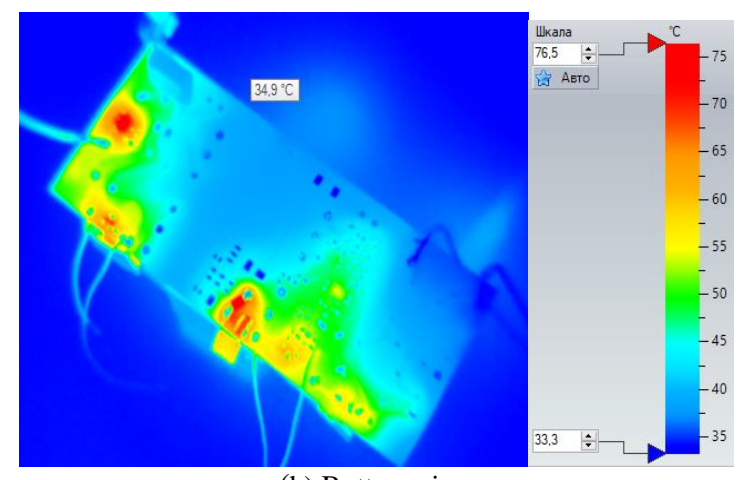

(b) Bottom view

Figure 9: Temperature map

As can be seen from the measurements, the main heat sources in the circuit are the key Q1 on the primary side, the output transistor of the passive stabilizer Q3 and the output diode D3 on the secondary side. The heating of these elements did not exceed 80 degrees, which lies within the permissible limits of the operation of these components.

Since this is an experimental sample, due to the lack of a casing and other heat-scattering elements, the components of the circuit were heated slightly above average. After refinement of the circuit, its dimensions will be reduced, in particular, the transformer will be reduced. Heat diffusers will also be added radiators and the case, more precisely it is planned to attach the heating elements transistors, keys and diodes to the metal case. This will significantly reduce the heating of these elements and increase the reliability and durability of the circuit.

\section{CONCLUSION}

A simplified control scheme has been developed - through the use of control on the primary side and a passive linear stabilizer. The proposed circuit uses a chip FL7733A. The standard circuit for the use of this chip is significantly inferior to that proposed by us. This is confirmed by functional tests. They show that at the output of the standard circuit there are current fluctuations at the input voltage frequency. They have a large effect on the flickering of LEDs and adversely affect their life. In the circuit we developed, this drawback is resolved by using a passive current regulator on the secondary side.

\section{ACKNOWLEDGEMENTS}

This work was carried out in the framework of grant financing 2018 / AP05132727 "Research and development of innovative LED power supply" with financial support from the Ministry of Science and Education of the Republic of Kazakhstan in 2018 2020

\section{REFERENCES}

1. Scale of LED Industrial lighting to reach US\$2.9 billion in 2016//www.ledinside.com/node/24822. March 2, 2016. Global LED \&smart street lighting (2016-2026)/ www.prnewswire.com, Jan 24, 2017.

2. Global LED and smart street lighting (2015-2025)/ www.northeast-group.com, Reportlinker/Vol 2, April 2015. Solutions for today's low-power LED lighting trends/ Bain Jonson, James Lee // www.fairchildsemi.com. March, 2012.

3. Van Ha Nguyen, Sanguk Nam, Kilsoo Seo, Yongsu Park, and Hanjung Song, "Low cost, high power factor, dimmable, monolithic, ac-direct LED driver with on chip step-dimmer for outdoor applications", International Journal on Engineering and Technology. Vol.8, No6, Dec.2016, - pp. 414-417. DOI: 10.7763/IJET.2016.V8.924.

4. H. Ma, W. Yu, Q. Feng, J. Lai and C. Zheng, "A novel SEPIC-derived PFC pre-regulator without electrolytic capacitor for PWM dimming LED lighting application based on valley fill circuit", 2011 IEEE Energy Conversion Congress and Exposition, Phoenix, AZ, Sep. 2011, pp. 23102317. DOI: 10.1109/ECCE.2011.6064075.

5. H. Ma, W. Yu, C. Zheng, J. Lai, Q. Feng and B. Chen, "A universal-input high-power-factor PFC pre-regulator without electrolytic capacitor for PWM dimming LED lighting application", 2011 IEEE Energy Conversion Congress and Exposition, Phoenix, AZ, Sept. 2011, pp. 2288-2295.DOI: 10.1109/ECCE.2011.6064072.

6. Y. Hu, L. Huber and M. M. Jovanović, "Single-Stage, Universal-Input AC/DC LED Driver With CurrentControlled Variable PFC Boost Inductor", in IEEE Transactions on Power Electronics, vol. 27, no. 3, pp. 15791588, March 2012, DOI: 10.1109/TPEL.2010.2082564.

7. M. Brkovic and S. Cuk, "Input current shaper using Cuk converter", [Proceedings] Fourteenth International Telecommunications Energy Conference - INTELEC '92, Washington, DC, USA, Aug.1992, pp. 532-539, DOI: $10.1109 /$ INTLEC.1992.268391. 
8. D. S. L. Simonetti, J. Sebastian and J. Uceda, "The discontinuous conduction mode Sepic and Cuk power factor preregulators: analysis and design", in IEEE Transactions on Industrial Electronics, vol. 44, no. 5, pp. 630-637, Oct. 1997, DOI: 10.1109/41.633459.

9. K. I. Hwu, Y. T. Yau and L. Lee, "Powering LED Using High-Efficiency SR Flyback Converter", in IEEE Transactions on Industry Applications, vol. 47, no. 1, pp. 376-386, Jan.-Feb. 2011, DOI: 10.1109/TIA.2010.2091234.

10. H.-S. Choi, "AN4151. Half-bridge LLC resonant converter design using Fairchild Power Switch (FPS)", Fairchild semiconductor, 2007.

11. Carbone, Rosario. "A passive power factor correction technique for single-phase thyristor-based controlled rectifiers", International Journal of Circuits, Systems and Signal Processing Vol.3, Iss.2, Mar. 2008, pp. 169-179.

12. Sum, K.K., "Improved valley-fill passive current shaper", Proc. Power Syst. World, Oct.1997, pp.1-8.

13. Yeh, T., "Analysis of power factor correction converters", Thesis. Rochester Institute of Technology, pgs 235, 1992.

14. Azazi, H. Z., E. E. El-Kholy, S. A. Mahmoud, and S. S. Shokralla. "Review of passive and active circuits for power factor correction in single phase, low power ACDC converters", Proceedings of the 14th International Middle East Power Systems Conference (MEPCON'10), Cairo University, Egypt, Dec.2010, pp. 217-224, Paper ID 154.

15. Single-Stage High Power Factor Flyback for LED Lighting/ Stockton Wu / Application Note AN012, May 2014.

16. Wen-Tien TSAI, Pingtung County (TW); Ching-Ran LEE, Kinmen County (TW); Po-Yen CHEN, Taipei City (TW); Ching-Tsai PAN, Hsinchu City (TW) "Passive power factor correction circuit, electronic device applying the same and operation methods thereof", US Patent 2014/0056046, Feb. 27, 2014.

17. Maxat Touzelbaev "Valley-Fill power factor correction circuit with active conduction angle control", US Patent 2015/0194883, Jul. 9, 2015.
18. L. Kim and M. W. Shin, "Implementation of Side Effects in Thermal Characterization of RGB Full-Color LEDs", in IEEE Electron Device Letters, vol. 28, no. 7, pp. 578-580, July 2007.

19. Y. Chung, K. Lee, H. Choe, C. Sung and B. Kang, "LowCost Drive Circuit for AC-Direct LED Lamps", in IEEE Transactions on Power Electronics, vol. 30, no. 10, pp. 57765782, Oct. 2015.

20. M. Uno and K. Sugiyama, "Switched Capacitor Converter Based Multiport Converter Integrating Bidirectional PWM and Series-Resonant Converters for Standalone Photovoltaic Systems", in IEEE Transactions on Power Electronics, vol. 34, no. 2, pp. 1394-1406, Feb. 2019.

21. F. Zhang and Y. Yan, "Novel Forward-Flyback Hybrid Bidirectional DC-DC Converter", in IEEE Transactions on Industrial Electronics, vol. 56, no. 5, pp. 1578-1584, May 2009.

22. Y. Qiu, L. Wang, H. Wang, Y. Liu and P. C. Sen, "Bipolar Ripple Cancellation Method to Achieve Single-Stage Electrolytic-Capacitor-Less High-Power LED Driver", in IEEE Journal of Emerging and Selected Topics in Power Electronics, vol. 3, no. 3, pp. 698-713, Sept. 2015.

23. User Guide for FEBFL7733A-L5U008A / Fairchild Semiconductor Corporation, 2014.

24. K.Sony, N.Durga Indira, S.Vinay Kumar, V.Bhanu Prakash, D.Jaya Chandra Sekhar. "Electronic Devices Monitoring based Wireless Gateway Network using Cisco Packet Tracer". International Journal of Advanced Trends in Computer Science and Engineering, Volume 8, No 6, pp. 29352939.

25. Cesar A. Llorente, Elmer P. Dadios. "Development and Characterization of a Dimmable LED Luminaire for Body Detection, Tracking and Recognition under Natural and Artificial Low-light Illumination". International Journal of Advanced Trends in Computer Science and Engineering, Volume 8, No 2, pp. 246-250.

https://doi.org/10.30534/ijatcse/2019/23822019 